\title{
Self-Management Apps for People With Epilepsy: Systematic Analysis
}

Mohsen Zaied Alzamanan ${ }^{1}$, MS; Kheng-Seang Lim², PhD; Maizatul Akmar Ismail ${ }^{3}$, PhD; Norjihan Abdul Ghani ${ }^{3}$, $\mathrm{PhD}$

${ }^{1}$ Department of Information Systems, University of Malaya, Kuala Lumpur, Malaysia

${ }^{2}$ Division of Neurology, Department of Medicine, Faculty of Medicine, University of Malaya, Kuala Lumpur, Malaysia

${ }^{3}$ Department of Information Systems, Faculty of Computer Science and Information Technology, University of Malaya, Kuala Lumpur, Malaysia

\section{Corresponding Author:}

Maizatul Akmar Ismail, PhD

Department of Information Systems

Faculty of Computer Science and Information Technology

University of Malaya

Jln Profesor Diraja Ungku Aziz

Kuala Lumpur, 50603

Malaysia

Phone: 60133476676

Email: maizatul@um.edu.my

\section{Abstract}

Background: Patients with epilepsy (PWEs) are motivated to manage and cope with their disorder themselves (ie, self-management $[\mathrm{SM}]$ is encouraged). Mobile health (mHealth) apps have multiple features that have a huge potential to improve SM of individuals with chronic disorders such as epilepsy.

Objective: This study aimed to review all freely available apps related to the SM of PWEs and to determine the SM domains covered in these apps.

Methods: We performed a search of apps on Google Play and App Store using the keywords "epilepsy" or "seizures" from May to August 2018. Apps were included if they were free and in English language. We excluded apps with installation-related issues and not related to epilepsy self-management (eSM).

Results: A total of 22 eSM apps were identified in our search: 6 of these run only on iOS, 7 only on Android, and 9 run on both operating systems. Of the 11 domains of SM, seizure tracking and seizure response features were covered by most apps ( $\mathrm{n}=22$ and $n=19$, respectively), followed by treatment management $(n=17)$ and medication adherence $(n=15)$. Three apps (Epilepsy Journal, Epilepsy Tool Kit, and EpiDiary) were installed more than 10,000 times, with features focused specifically on a few domains (treatment management, medication adherence, health care communication, and seizure tracking). Two apps (Young Epilepsy and E-Epilepsy Inclusion) covered more than 6 SM domains but both had lower installation rates (5000+ and 100+, respectively).

Conclusions: Both Android and iOS mHealth apps are available to improve SM in epilepsy, but the installation rate of most apps remains low. The SM features of these apps were different from one another, making it difficult to recommend a single app that completely fulfills the needs of PWEs. The common features of the apps evaluated included seizure tracking and seizure response. To improve the efficacy and availability of these apps, we propose the following: (1) involve the stakeholders, such as physicians, pharmacists, and PWEs, during the development of mHealth apps; (2) assess the efficacy and acceptance of the apps objectively by performing a usability analysis; and (3) promote the apps so that they benefit more PWEs.

(JMIR Mhealth Uhealth 2021;9(5):e22489) doi: 10.2196/22489

\section{KEYWORDS}

mobile health; epilepsy; self-management; smartphone 


\section{Introduction}

Epilepsy affects approximately 50 million people of all ages worldwide, irrespective of race and economic background [1,2]. It is estimated that nearly 200,000 individuals living in Malaysia have epilepsy [3]. According to the World Health Organization, epilepsy is one of the most common neurological diseases [4]. Patients with epilepsy (PWEs) face many challenges related to their disease as well as to their families and health care providers (HCPs) [5]; additionally, lack of disease control affects the patients' work, relationship, and daily responsibilities [6]. HCPs also find it hard to monitor their PWEs to understand if any of their symptoms are improving or if they are experiencing any new symptoms [7]. In Malaysia, based on our experience, most PWEs use the calendar for seizure monitoring and some also record their medications on it.

PWEs are encouraged to self-manage their condition, as this has been proven to improve quality of life and considers the priority of their care [8]. However, the features of existing apps vary from one another, making it difficult to recommend one that is most complete to fulfill the needs of PWEs.

Self-management (SM) is generally defined as an individual's ability to manage the symptoms, treatment, physical and psychosocial consequences, and lifestyle modifications necessary when living with a chronic disease [9]. SM is a dynamic process, which includes steps and decisions taken daily in response to living with a chronic condition [9]. In this process, patients are empowered for changing their health behavior via better knowledge about their disease and treatment, and by managing symptoms and physical/psychosocial consequences of the disease [10]. Patients need to rely on their self to manage their disorder daily [11].

The Institute of Medicine advocates the development of epilepsy self-management (eSM) programs to ensure the patients benefit from technologies such as computers and mobile devices [12]. Mobile health (mHealth) apps, including eSM apps, present daily companions of health data which help patients and health care professionals improve health outcomes [13] through constant monitoring of the patient's status.

mHealth apps play a major role among patients with chronic disease in managing their disorders [14]. According to one report, there were 325,000 mHealth apps on the market in 2017 [15]. There are about $165,000 \mathrm{mHealth}$ apps in major app stores and most of these relate to management of diseases [16].

Many studies have found that mobile apps can assist patients with chronic condition [17]. Recently, a multitude of mHealth apps have been launched and shown to improve chronic disease care in patients with diabetes mellitus, hypertension, and other disorders [12,14,18].

The use of smartphone apps could be a promising strategy for seizure SM [14]. Nearly $94.4 \%$ of PWEs owned a smartphone; thus, it could be said that there is a positive attitude toward using epilepsy apps among PWEs [14].

This study aimed to perform a systematic review to identify the free eSM apps available in Apple App Store and Google Play app stores and to identify the domains covered by these eSM apps.

\section{Methods}

\section{Study Overview}

In this study we performed a systematic review of all apps that relate to PWEs and help these patients manage their disorder. We searched for eSM apps in both iOS (App Store) and Android (Google Play) app stores.

\section{Research Questions}

This study aimed to answer the following 3 questions:

- Research Question 1: What are the apps available to help in eSM?

- Research Question 2: What are the features of these apps?

- Research Question 3: What is the user rating of mobile apps related to eSM?

\section{Inclusion Criteria}

We performed a search of apps on Google Play and App Store using the keywords "epilepsy" or "seizures" from May to August 2018. The research was conducted in Malaysia; therefore, we included only Android and iOS apps, as only these are available in the country.

Inclusion criteria for choosing mobile apps were as follows: available in English, can be freely downloaded, and intended for individuals with epilepsy, covering at least one of the 11 domains described by Escoffery et al [9], which include health care communication, social support, medication adherence, treatment management, seizure response, wellness, stress management, coping and stress management, seizure tracking, safety, and proactivity.

\section{Exclusion Criteria}

Apps with installation issues or in other languages were excluded.

\section{Review Process}

To assess the quality of the apps and risk of bias, we first read and reviewed the app's description on the download page, to ascertain that the app fulfilled the inclusion or exclusion criteria. However, the app description alone is not enough to assess the app's quality [19], and therefore all selected apps were downloaded for further analysis [19]. A user's rating scale (score range 0-5) was used to determine the quality of the apps, with 5 indicating the best quality.

\section{Results}

\section{Search Strategy and App Characteristics}

A total of 382 mobile apps were found in the 2 app stores: 241 for Android and 141 for iOS. Apps that were not in English and not free were excluded $(n=104)$, thus eventually 278 apps were downloaded for analysis. Next, we reviewed the description of each app to determine its features and purposes and excluded 235 apps, such as conference (meeting), games, and flashlights, which were not related to eSM. Eventually, 43 apps fulfilled 
our criteria covering 1 or more eSM domains described by [9], of which 11 were compatible with both Android and iOS. We included $32 \mathrm{eSM}$ apps for further analysis; however, 10 of these apps were excluded because of installation issues or they were malfunctioning. Table 1 presents the reasons for excluding the 10 apps during the installing stage. Of the final 22 included for analysis, 6 (27\%) run on iOS, 7 (32\%) on Android, and 9 (41\%) on both operating systems. A PRISMA flow diagram showing the app selection process is presented in Figure 1. All 22 apps enhance eSM; however, none of the apps indicated whether any of the stakeholders, such as physicians, pharmacists, and PWEs, had participated in the app development process.

Most apps are generally complicated and the PWEs has to learn how to enter their data on the app, thereby affecting the potential use of these apps. Patients with chronic diseases such as epilepsy need a user-friendly app. As it is imperative that the content and features of epilepsy support apps motivate and support PWEs to manage their illness, PWEs and HCPs should be given an opportunity to participate and collaborate in developing a mobile app for eSM. The home page for each app contains a brief description about the app to convince the users to download it. This is especially the case with paid apps [19]. However, some app descriptions do not reflect the actual features and functions of the app. None of the apps indicated on their home page whether they have managed to achieve their goals through acceptance by the users. There was also no statement about the participation of stakeholders while developing the apps.

Table 1. Epilepsy self-management apps with issues during the installation stage.

\begin{tabular}{lll}
\hline App name & Operating system & Issue \\
\hline Total Epilepsy Recorder & iOS & Error message \\
Seizure Sync Epilepsy Log & iOS & Error message \\
Fable Epilepsy Charity & iOS & App has been temporarily disabled by publisher \\
Wacean & iOS & Error message \\
Epilepsy Tracl & Android & This is currently a work in progress \\
Seizure Tracker & Android & Error message \\
Seizure Sync Epilepsy Manager & Android & Error message \\
Total Epilepsy & Android & Installation issue \\
Alert & Android & Installation issue \\
Dr. Epilepsy & Android & Installation issue \\
\hline
\end{tabular}


Figure 1. PRISMA flow diagram.

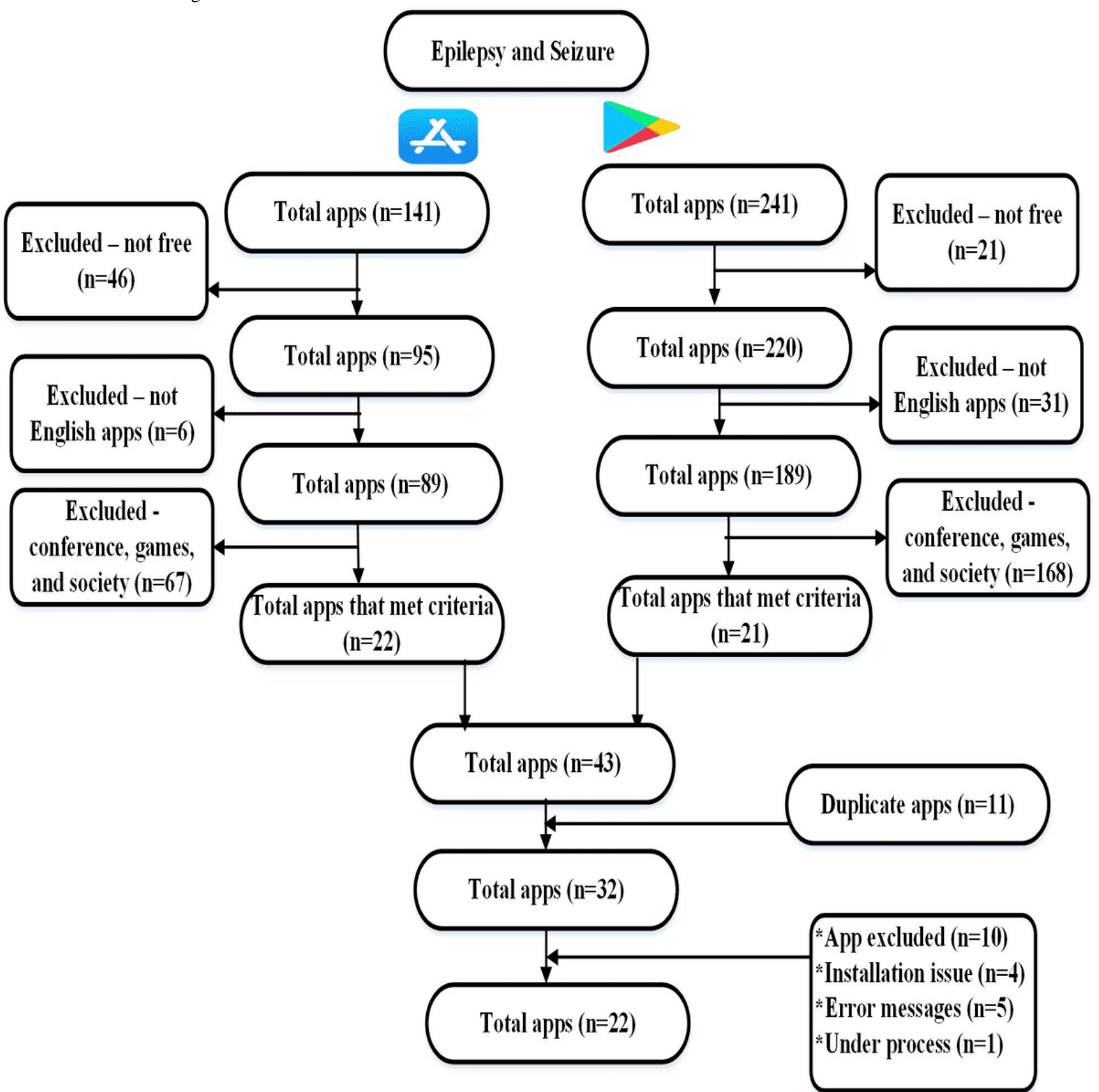

\section{User's Rating}

We used the apps' home page to obtain the user ratings. Table 2 presents the average user rating for the apps.
The ratings shown in Table 2 also depict the popularity of certain apps, as rated by the users. An app is usually considered popular if the users are happy with it, which eventually provides an indication of its usefulness. 
Table 2. App user rating.

\begin{tabular}{|c|c|c|c|}
\hline Name (app developer) & Number of installations & Average user rating & Number of raters \\
\hline Epilepsy Journal (Olly Tree Application) & $10,000+$ & 4.4 & 176 \\
\hline Epilepsy Tool Kit (Epilepsy Society) & $10,000+$ & 3.9 & 79 \\
\hline EpiDiary (EpiDiary Irody, Inc.) & $10,000+$ & 3.5 & 345 \\
\hline Young Epilepsy (Synergix Health Ltd.) & $5000+$ & 4.1 & 88 \\
\hline Seizure Log (Seizure Tracker LLC) & $5000+$ & 4.7 & 9 \\
\hline Simple Seizure $\left(\mathrm{NA}^{\mathrm{a}}\right)$ & $5000+$ & 4.4 & 176 \\
\hline My Seizure Diary (Epilepsy Foundation) & $5000+$ & 2.2 & 52 \\
\hline Epilepsy Ireland Diary App (DXC Technology) & $1000+$ & 3.1 & 11 \\
\hline Seizure First Aide (Afixia LLC) & $1,000+$ & 3.4 & 12 \\
\hline Win Over Epilepsy (WOE) (Bee Mobile Pvt. Ltd.) & $500+$ & 4.6 & 19 \\
\hline Birdhouse - for Epilepsy (Birdhouse LLC) & $500+$ & 3.0 & 2 \\
\hline EpApp (PENNSW \& The Sydney Children's Hospitals Network) & $100+$ & 3.8 & 8 \\
\hline BioMark Health Epilepsy (NA) & $100+$ & 4.7 & 12 \\
\hline E-Action Info (The ImageFactory) & $100+$ & 4.00 & 2 \\
\hline E-Epilepsy Inclusion (The Hong Kong Society for Rehabilitation) & $100+$ & 4.9 & 7 \\
\hline ElFY Epilepsy (ELFY APP) & $10+$ & 5.00 & 2 \\
\hline Helpilepsy - Epilepsy Assistant \& Diary (M4KEIT) & $500+$ & 4.8 & 8 \\
\hline Epilepsy Help (Dr. Bindu Menon Foundations) & $-\mathrm{b}$ & 4.8 & 16 \\
\hline Epilepsy Safe (Comalf) & - & 3.7 & 6 \\
\hline Epi \& Me 2 (HandMe) & - & 0 & - \\
\hline M.E. (Epilepsy Foundation of New Jersey) & - & 0 & - \\
\hline SAMi3 Sleep Activity Monitor (HiPass Design LIC) & - & - & 0 \\
\hline
\end{tabular}

${ }^{\mathrm{a}} \mathrm{NA}$ : not available.

b_: Not applicable

\section{Domains of Self-Management}

Apps analyzed covered a total of 11 domains. The common domains were seizure tracking and seizure response, followed by treatment management and medication adherence. Three apps (Epilepsy Journal, Epilepsy Tool Kit, and EpiDiary) were installed more than 10,000 times, with their features specifically focusing on a few domains (treatment management, medication adherence, health care communication, and seizure tracking).
Two apps covered over 6 SM domains (Young Epilepsy and E-Epilepsy Inclusion); however, both had lower installation rates $(5000+$ and $100+$, respectively). Apps available only in Google Play or both Google Play and App Store had higher installation rates than the those available in App Store only $(n=6)$, which include Seizure First Aide, E-Epilepsy Inclusion, ElFY Epilepsy, Epi \& Me 2, M.E., and SAMi3 Sleep Activity Monitor (Tables 2 and 3). 
Table 3. Name of the apps identified in this study and their eSM features $(n=22)$.

\begin{tabular}{|c|c|c|}
\hline App name (developer) & Operating system & Self-management features \\
\hline $\begin{array}{l}\text { Epilepsy Journal (Olly Tree Appli- } \\
\text { cation) }\end{array}$ & Android & $\begin{array}{l}\text { Helps to track seizure frequency; identify the effectiveness of epilepsy treatments; and } \\
\text { input data on symptoms related to epilepsy that help HCPs to adjust medication dose or } \\
\text { change the medication }\end{array}$ \\
\hline $\begin{array}{l}\text { Epilepsy Tool Kit (Epilepsy Soci- } \\
\text { ety) }\end{array}$ & Both & Uses a new and interactive way by which it helps PWEs to manage their epilepsy \\
\hline EpiDiary (EpiDiary Irody, Inc.) & Android & Keeps track of seizures, medicines, sleep, and how one feels daily \\
\hline $\begin{array}{l}\text { Young Epilepsy (Synergix Health } \\
\text { Ltd.) }\end{array}$ & Both & $\begin{array}{l}\text { Useful for young people with epilepsy and for parents or caregivers of a child who has } \\
\text { epilepsy. Provides up-to-date information and has portal, video, and diary functionalities } \\
\text { that help track seizures and manage symptoms }\end{array}$ \\
\hline Seizure Log (Seizure Tracker LLC) & Both & Records seizure attacks \\
\hline Simple Seizure $\left(\mathrm{NA}^{\mathrm{a}}\right)$ & Android & Used as a diary to manage epilepsy \\
\hline $\begin{array}{l}\text { My Seizure Diary (Epilepsy Founda- } \\
\text { tion) }\end{array}$ & Both & $\begin{array}{l}\text { Epilepsy management includes self-monitoring and tracking, managing medications, and } \\
\text { communicating with health care providers }\end{array}$ \\
\hline $\begin{array}{l}\text { Epilepsy Ireland Diary App (DXC } \\
\text { Technology) }\end{array}$ & Both & Used to track and record seizures and also determine trigger factors \\
\hline Seizure First Aide (Afixia LLC) & iOS & Educates about epilepsy \\
\hline $\begin{array}{l}\text { Win Over Epilepsy (WOE) (Bee } \\
\text { Mobile Pvt. Ltd.) }\end{array}$ & Android & Helps to keep track of seizures, medicines, visits, etc. \\
\hline $\begin{array}{l}\text { Birdhouse - for Epilepsy (Birdhouse } \\
\text { LLC) }\end{array}$ & Both & $\begin{array}{l}\text { Helps to identify seizure triggers, manage a medication log, evaluate diets, and ensure } \\
\text { the path to success }\end{array}$ \\
\hline $\begin{array}{l}\text { EpApp (PENNSW \& The Sydney } \\
\text { Children's Hospitals Network) }\end{array}$ & Both & $\begin{array}{l}\text { Provides information about epilepsy; also has a tool that supports self-management for } \\
\text { PWEs and their parents }\end{array}$ \\
\hline BioMark Health Epilepsy (NA) & Android & $\begin{array}{l}\text { Offers multiple functionalities (eg, passive data collection, medication reminders, quan- } \\
\text { tified self-data collection, and care-team management) to understand epilepsy better and } \\
\text { achieve more peace of mind for caregivers }\end{array}$ \\
\hline E-Action Info (The ImageFactory) & Both & Teaches and increases the knowledge on epilepsy in a fun and easy way \\
\hline $\begin{array}{l}\text { E-Epilepsy Inclusion (The Hong } \\
\text { Kong Society for Rehabilitation) }\end{array}$ & iOS & $\begin{array}{l}\text { Assists in enhancing epilepsy self-management; helps to communicate with health care } \\
\text { providers; and educates the public about epilepsy }\end{array}$ \\
\hline ElFY Epilepsy (ELFY APP) & iOS & Tracks the right medication every day \\
\hline $\begin{array}{l}\text { Helpilepsy - Epilepsy Assistant \& } \\
\text { Diary (M4KEIT) }\end{array}$ & Both & Assists, tracks, and shares epilepsy records more easily and effectively \\
\hline $\begin{array}{l}\text { Epilepsy Help (Dr. Bindu Menon } \\
\text { Foundations) }\end{array}$ & Android & $\begin{array}{l}\text { Helps patients with epilepsy to organize and upload their medical data, keep medicine } \\
\text { alarm and seizure alert, track appointment schedule, and know about epilepsy }\end{array}$ \\
\hline Epilepsy Safe (Comalf) & Android & Helps to receive emergency aid from passersby in case of seizure attack in a public place \\
\hline Epi \& Me 2 (HandMe) & iOS & $\begin{array}{l}\text { Assists in epilepsy management such as collecting and storing data on seizures, medication } \\
\text { adherence, and life circumstances }\end{array}$ \\
\hline $\begin{array}{l}\text { M.E. (Epilepsy Foundation of New } \\
\text { Jersey) }\end{array}$ & iOS & Useful for people with epilepsy and their families to manage their epilepsy \\
\hline $\begin{array}{l}\text { SAMi3 Sleep Activity Monitor } \\
\text { (HiPass Design LIC) }\end{array}$ & iOS & $\begin{array}{l}\text { Monitors the sleep activity of the patient for the caregiver and family members to carefully } \\
\text { observe for any abnormal movement at night }\end{array}$ \\
\hline
\end{tabular}

${ }^{\mathrm{a} N A}$ : not available.

\section{Mobile App Description}

This section describes the 22 apps which have been identified through this systematic review. Table 3 presents the name of the app and the self-management features included, while the eSM domain(s) they cover are listed in Table 4. 
Table 4. App names and domains of self-management.

\begin{tabular}{|c|c|c|c|c|c|c|c|c|c|c|c|c|}
\hline App name & $\begin{array}{l}\text { Treat- } \\
\text { ment } \\
\text { manage- } \\
\text { ment }\end{array}$ & $\begin{array}{l}\text { Medica- } \\
\text { tion ad- } \\
\text { herence }\end{array}$ & $\begin{array}{l}\text { Health } \\
\text { care } \\
\text { commu- } \\
\text { nication }\end{array}$ & $\begin{array}{l}\text { Seizure } \\
\text { tracking }\end{array}$ & $\begin{array}{l}\text { Seizure } \\
\text { re- } \\
\text { sponse }\end{array}$ & Safety & $\begin{array}{l}\text { Well- } \\
\text { ness }\end{array}$ & $\begin{array}{l}\text { Social } \\
\text { support }\end{array}$ & Coping & $\begin{array}{l}\text { Stress } \\
\text { manage- } \\
\text { ment }\end{array}$ & $\begin{array}{l}\text { Proactiv- } \\
\text { ity }\end{array}$ & $\begin{array}{l}\text { Total } \\
\text { domains }\end{array}$ \\
\hline Epilepsy Journal & $\checkmark$ & $\checkmark$ & $\checkmark$ & $\checkmark$ & & & & & & & & 4 \\
\hline Epilepsy Tool Kit & $\checkmark$ & $\checkmark$ & $\checkmark$ & $\checkmark$ & $\checkmark$ & $\checkmark$ & & & & & & 6 \\
\hline My Seizure Diary & $\checkmark$ & $\checkmark$ & $\checkmark$ & $\checkmark$ & $\checkmark$ & & & $\checkmark$ & & & & 6 \\
\hline EpApp & $\checkmark$ & & $\checkmark$ & $\checkmark$ & $\checkmark$ & & & & & & & 4 \\
\hline Young Epilepsy & $\checkmark$ & $\checkmark$ & $\checkmark$ & $\checkmark$ & $\checkmark$ & $\checkmark$ & $\checkmark$ & $\checkmark$ & $\checkmark$ & $\checkmark$ & & 10 \\
\hline $\begin{array}{l}\text { Helpilepsy - Epilepsy } \\
\text { Assistant \& Diary }\end{array}$ & $\checkmark$ & $\checkmark$ & & $\checkmark$ & $\checkmark$ & & & & & & & 4 \\
\hline EpiDiary & $\checkmark$ & $\checkmark$ & $\checkmark$ & $\checkmark$ & & & & & & & & 4 \\
\hline Simple Seizure & & & $\checkmark$ & $\checkmark$ & $\checkmark$ & & & & & & & 3 \\
\hline Epilepsy Help & $\checkmark$ & $\checkmark$ & & $\checkmark$ & $\checkmark$ & $\checkmark$ & & & & & $\checkmark$ & 6 \\
\hline $\begin{array}{l}\text { BioMark Health } \\
\text { Epilepsy }\end{array}$ & $\checkmark$ & $\checkmark$ & & $\checkmark$ & $\checkmark$ & & & & & & & 4 \\
\hline $\begin{array}{l}\text { Epilepsy Ireland Di- } \\
\text { ary App }\end{array}$ & & & $\checkmark$ & $\checkmark$ & $\checkmark$ & & & & & & & 3 \\
\hline Epilepsy Safe & $\checkmark$ & $\checkmark$ & $\checkmark$ & $\checkmark$ & & & & $\checkmark$ & & & & 5 \\
\hline $\begin{array}{l}\text { Win Over Epilepsy } \\
\text { (WOE) }\end{array}$ & $\checkmark$ & $\checkmark$ & $\checkmark$ & $\checkmark$ & $\checkmark$ & & & $\checkmark$ & & & & 6 \\
\hline $\begin{array}{l}\text { Birdhouse - for } \\
\text { Epilepsy }\end{array}$ & $\checkmark$ & $\checkmark$ & $\checkmark$ & $\checkmark$ & $\checkmark$ & $\checkmark$ & & & & & & 6 \\
\hline E-Action Info & $\checkmark$ & $\checkmark$ & $\checkmark$ & $\checkmark$ & $\checkmark$ & $\checkmark$ & & & & & & 6 \\
\hline E-Epilepsy Inclusion & $\checkmark$ & $\checkmark$ & $\checkmark$ & $\checkmark$ & $\checkmark$ & $\checkmark$ & & & $\checkmark$ & $\checkmark$ & $\checkmark$ & 9 \\
\hline ElFY Epilepsy & $\checkmark$ & $\checkmark$ & $\checkmark$ & $\checkmark$ & $\checkmark$ & & $\checkmark$ & & & & & 6 \\
\hline Seizure Log & $\checkmark$ & & $\checkmark$ & $\checkmark$ & $\checkmark$ & & & & & & & 4 \\
\hline Epi \& Me 2 & $\checkmark$ & $\checkmark$ & & $\checkmark$ & $\checkmark$ & & & & & & & 4 \\
\hline Seizure First Aide & & & & $\checkmark$ & $\checkmark$ & $\checkmark$ & & & & & & 3 \\
\hline M.E. & & & & $\checkmark$ & $\checkmark$ & & & & & & & 2 \\
\hline $\begin{array}{l}\text { SAMi3 Sleep Activity } \\
\text { Monitor }\end{array}$ & & & & $\checkmark$ & $\checkmark$ & $\checkmark$ & & & & & & 3 \\
\hline
\end{tabular}

\section{Treatment Management}

A total of 17/22 apps (77\%; eg, Epilepsy Journal, Epilepsy Tool Kit, Young Epilepsy, Epilepsy Help, Epi \& Me 2) help patients self-manage their treatment. The common features in these apps were a reminder for treatment, appointment, and recommendations and advice of HCPs that should be followed.

\section{Medication Adherence}

A total of 15 apps, such as the Epilepsy Journal, My Seizure Diary, Birdhouse - for Epilepsy, EpiDiary, BioMark Health Epilepsy, Win Over Epilepsy (WOE), ElFY Epilepsy, and Seizure $\log$, were found to have features related to medication adherence. These apps enabled PWEs to establish and record a medication list, including the number of repeats remaining, the personalized dose, how many days the supply would last, and an alert reminder. Moreover, they provide PWEs a chance to register their time of medication, type of medication received, and frequency of acquiring the medication with their medication photo attached.

\section{Health Care Communication}

The success of the patient-centered model depends on communication between HCPs and patients [20], which strengthens their relationship and facilitates better treatment. In our study, 16 apps (73\%), such as E-Epilepsy Inclusion, Simple Seizure Diary, Epilepsy Tool Kit, and Epi \& Me, covered health care communication. These apps allow the PWEs to send their reports to their HCPs through email or share it as an efile during an appointment. This feature helps patients, caregivers, and HCPs to establish a relationship, which is extremely important. In addition, some apps allow the patient and HCPs to monitor the side effects of epilepsy, such as depression, anxiety, unstable emotions, and sleep problems. 


\section{Seizure Tracking}

Seizure tracking provides critical information that helps the health care professional to evaluate the medication and health treatment received by the patients. All the apps cover seizure tracking and provide the features of tracking, such as registration of seizure time, duration, type and frequency of seizure, seizure triggers, and video recordings of the seizure.

\section{Seizure Response}

In our study, 19 apps (86\%), such as Young Epilepsy, Seizure First Aide, Help Epilepsy, Seizure Log, BioMark Health Epilepsy, Epilepsy Tool Kit, Epilepsy Ireland Diary App, and Epilepsy Safe, cover the domain of seizure response. These apps include features such as first-aid instructions on how one can help someone when they have a seizure and when to dial 999. A customized emergency SMS text message can be sent with a touch of a button during the aura stage or following a seizure. The user can automatically send an alert message (with GPS location) to his/her family through the Epilepsy Safe app.

\section{Safety}

Eight apps (36\%), such as Birdhouse - for Epilepsy and E-Action Info, covered the safety domain, which relates to avoiding risks that are detrimental to PWEs. One app from the App Store provided information for patients regarding the course of action during a seizure attack.

\section{Wellness}

Three apps, namely, ElFY Epilepsy, Birdhouse - for Epilepsy, and Young Journal, covered the wellness domain (compatible with both iOS and Android) and provide the PWEs with some type of wellness-related information, such as diet and exercise. The Birdhouse - for Epilepsy app also tracks food consumption to help identify associations with seizure activity.

\section{Social Support}

Four apps, namely, My Seizure Diary, Young Epilepsy, Epilepsy Safe, and Win Over Epilepsy, covered the social support domain and contained some stories related to epilepsy. This domain includes sharing stories or experiences with PWEs and getting some advice regarding epilepsy.

\section{Coping and Stress Management}

Coping, stress management, and proactivity are less popular domains and are included in only 2 apps, namely, ElFY Epilepsy and Young Epilepsy. These cover topics on managing stress; doing something that reduces sadness; and encourage PWEs to continue hobbies, relaxation, or exercises that help prevent seizure.

\section{Proactivity}

Only 2 apps provided some information related to proactivity (Epilepsy Help and E-Epilepsy Inclusion), and included some advice that may avoid situations or things that might cause a seizure.

\section{Discussion}

\section{Principal Findings}

In this review, $22 \mathrm{SM}$ apps for epilepsy were found. The apps with the highest installation frequency were Epilepsy Journal, Epilepsy Tool Kit, and EpiDiary (10,000+ for each), and these cover the 4 most important domains of eSM, namely, treatment management, medication adherence, health care communication, and seizure tracking. However, as nearly 50 million people are estimated to have epilepsy worldwide [1,2], these apps are underutilized.

Monitoring seizure episodes assists in increasing the possibility of capturing seizures and tracking the evolution of the disease [21]. Using paper diaries to collect data related to patient's symptoms is a challenging task. Thus, mobile apps have become a great tool that help PWEs to cope with and control their condition. These apps also aid PWEs to record their data and evaluate the effect of medication and treatment administered in consultation with their HCPs. A well-designed app provides a good opportunity for both PWEs and HCPs to manage epilepsy and select the best option together.

Apps with the highest download/installation frequency reflect increased acceptability by users, despite covering less domains. Most of these apps focus on seizure tracking because this provides valuable information that helps in the management of the disease [21]. A high percentage $(60 \%-70 \%)$ of patients can become seizure free when they promptly take the effective medication. Adherence is defined by the World Health Organization as "the extent to which a person's behavior - taking medication, following a diet, and executing lifestyle changes-corresponds with the agreed recommendations from a HCP" [22].

However, finding an appropriate antiepileptic drug (AED) can be a long and challenging process because patients struggle to report their seizure frequency [23]. Providing seizure information remains critical to help neurologists in selecting the correct dose of AEDs for their patients; efficiency of AED in long-term treatments should also be evaluated [23].

Nonadherence is a critical issue for PWEs [24] and can lead to an increase in seizure frequency [25]. PWEs generally do not adhere to their medication, which negatively affects their situation [26]. Nonadherence to medications usually decreases the quality of treatment outcomes, maximizes the consultations and hospitalization, and increases the health care cost [27]. Despite the risks associated with not taking medications, 50\% of the patients with a chronic condition fail to adhere to their treatment recommendations [22]. Adherence requires active involvement of the patient and a therapeutic alliance between the patient and his/her physician [28]. Therefore, most apps have features to support medication management.

According to our review, most of the apps cover at least one or more domains of eSM, as recommended by the World Health Organization [4]. Each app has features that allow PWEs to self-manage epilepsy. However, not all the apps analyzed covered all 11 domains. Every app focused on different domains of eSM. The Young Epilepsy app is the only one that covered 
most (10 overall) eSM domains (user rating: 4.4), whereas the My Seizure Diary app covered only 6 domains and had the lowest user rating (2.2).

Without effective management, PWEs will have poor quality of life, and so mHealth apps are considered promising tools that will assist and fill the gap in eSM. End users should be part of design and development stages of apps to increase the quality of apps and achieve the app's intended goal(s).

\section{Study Limitations}

We only included English apps because this study aimed to review the current epilepsy apps from an international perspective, and not just from a Malaysian perspective. However, the apps were accessed through the Malaysian App Store and Google Play sites as stated in the "Methods" section. The research was conducted in Malaysia, and the apps that are available for iOS and Android in this country differ from those in the United States, while some are not available in our country, which possibly affects the overall analysis. The study included only free apps. Some with reasonable prices might be added to make the study more valuable. Many apps were excluded from the study because their languages were not English, although some of these have great features. Only Android- and iOS-compatible apps were targeted in this research. However, many related apps could be available for other mobile operating systems, such as BlackBerry or LiteOS (Huawei).

\section{Conclusion and Future Work}

A total of 22 apps were found to support different eSM domains; however, almost all of these were underutilized (ie, had less installation rate). Thus, to improve the efficacy and availability of these apps, we propose the following: (1) involve various stakeholders, such as physicians, pharmacists, and PWEs, during the development of mHealth apps; (2) assess the efficacy and acceptance of these apps objectively by performing a usability analysis; and (3) promote the apps so that they benefit more PWEs. Malaysia is a multiracial country which is dominated by 3 racial groups, namely, Malay, Indian, and Chinese. In the future, we will also analyze similar apps in local languages to ensure all important features are considered.

\section{Acknowledgments}

We thank Hussain Mutlaq Alnajrani, MS, University of Malaya, who assisted us with app installation to review the mobile apps. This study is self-funded.

\section{Conflicts of Interest}

None declared.

\section{References}

1. Amorim P, Moraes T, Fazanaro D, Silva J, Pedrini H. Electroencephalogram signal classification based on shearlet and contourlet transforms. Expert Systems with Applications 2017 Jan;67:140-147. [doi: 10.1016/j.eswa.2016.09.037]

2. Velasquez SE, Chaves-Carballo E, Nelson E. Pediatric Teleneurology: A Model of Epilepsy Care for Rural Populations. Pediatric neurology 2016 Nov;64:32-37. [doi: 10.1016/j.pediatrneurol.2016.08.001] [Medline: 27742162]

3. Norsa'adah B, Zainab J, Knight A. The quality of life of people with epilepsy at a tertiary referral centre in Malaysia. Health and quality of life outcomes 2013 Aug 23;11(1):1-6 [FREE Full text] [doi: 10.1186/1477-7525-11-143] [Medline: 23972031]

4. World Health Organization. Atlas: Epilepsy Care in the World. Geneva, Switzerland: World Health Organization; 2005.

5. England MJ, Liverman CT, Schultz AM, Strawbridge LM. Epilepsy across the spectrum: promoting health and understanding. A summary of the Institute of Medicine report. Epilepsy \& Behavior 2012 Oct;25(2):266-276 [FREE Full text] [doi: 10.1016/j.yebeh.2012.06.016] [Medline: 23041175]

6. Dannenberg M, Mengoni SE, Gates B, Durand M. Self-management interventions for epilepsy in people with intellectual disabilities: A scoping review. Seizure 2016 Oct;41:16-25 [FREE Full text] [doi: 10.1016/j.seizure.2016.06.022] [Medline: 27447692]

7. Helmers SL, Kobau R, Sajatovic M, Jobst BC, Privitera M, Devinsky O, Centers for Disease ControlPrevention Managing Epilepsy Well Network. Self-management in epilepsy: Why and how you should incorporate self-management in your practice. Epilepsy \& Behavior 2017 Mar;68:220-224 [FREE Full text] [doi: 10.1016/j.yebeh.2016.11.015] [Medline: 28202408]

8. Leenen LA, Wijnen BF, de Kinderen RJ, van Heugten CM, Evers SM, Majoie MH. Are people with epilepsy using eHealth-tools? Epilepsy \& Behavior 2016 Nov;64(Pt A):268-272. [doi: 10.1016/j.yebeh.2016.08.007] [Medline: 27780086]

9. Escoffery C, Bamps Y, LaFrance WC, Stoll S, Shegog R, Buelow J, et al. Factor analyses of an Adult Epilepsy Self-Management Measurement Instrument (AESMMI). Epilepsy \& Behavior 2015 Sep;50:184-189. [doi: 10.1016/j.yebeh.2015.07.026] [Medline: 26264465]

10. Leenen LA, Wijnen BF, de Kinderen RJ, Majoie MH, van Heugten CM, Evers SM. (Cost)-effectiveness of a multi-component intervention for adults with epilepsy: study protocol of a Dutch randomized controlled trial (ZMILE study). BMC neurology 2014 Dec 24;14(1):255 [FREE Full text] [doi: 10.1186/s12883-014-0255-3] [Medline: 25540089]

11. Hale K, Capra S, Bauer J. A Framework to Assist Health Professionals in Recommending High-Quality Apps for Supporting Chronic Disease Self-Management: Illustrative Assessment of Type 2 Diabetes Apps. JMIR Mhealth Uhealth 2015 Sep 14;3(3):e87 [FREE Full text] [doi: 10.2196/mhealth.4532] [Medline: 26369346] 
12. Pandher PS, Bhullar KK. Smartphone applications for seizure management. Health informatics journal 2016 Jun 18;22(2):209-220 [FREE Full text] [doi: 10.1177/1460458214540906] [Medline: 25038202]

13. Bulaj G. Combining non-pharmacological treatments with pharmacotherapies for neurological disorders: a unique interface of the brain, drug-device, and intellectual property. Frontiers in neurology 2014 Jul 14;5:126 [FREE Full text] [doi: 10.3389/fneur.2014.00126] [Medline: 25071711]

14. Liu X, Wang R, Zhou D, Hong Z. Feasibility and acceptability of smartphone applications for seizure self-management in China: Questionnaire study among people with epilepsy. Epilepsy \& Behavior 2016 Feb;55:57-61. [doi: 10.1016/j.yebeh.2015.11.024] [Medline: 26745631]

15. Paglialonga A, Schiavo M, Caiani EG. Automated Characterization of Mobile Health Apps' Features by Extracting Information From the Web: An Exploratory Study. Am J Audiol 2018 Nov 19;27(3S):482-492. [doi: $10.1044 / 2018$ aja-imia3-18-0008]

16. Mendiola MF, Kalnicki M, Lindenauer S. Valuable features in mobile health apps for patients and consumers: content analysis of apps and user ratings. JMIR Mhealth Uhealth 2015 May 13;3(2):e40 [FREE Full text] [doi: 10.2196/mhealth.4283] [Medline: 25972309]

17. Hilliard ME, Hahn A, Ridge AK, Eakin MN, Riekert KA. User Preferences and Design Recommendations for an mHealth App to Promote Cystic Fibrosis Self-Management. JMIR Mhealth Uhealth 2014 Oct 24;2(4):e44 [FREE Full text] [doi: 10.2196/mhealth.3599] [Medline: 25344616]

18. Eng DS, Lee JM. The promise and peril of mobile health applications for diabetes and endocrinology. Pediatric diabetes 2013 Jun 30;14(4):231-238 [FREE Full text] [doi: 10.1111/pedi.12034] [Medline: 23627878]

19. BinDhim NF, Hawkey A, Trevena L. A systematic review of quality assessment methods for smartphone health apps. Telemedicine and e-Health 2015 Feb;21(2):97-104. [doi: 10.1089/tmj.2014.0088] [Medline: 25469795]

20. Shegog R, Begley CE, Harding A, Dubinsky S, Goldsmith C, Hope O, et al. Description and feasibility of MINDSET: A clinic decision aid for epilepsy self-management. Epilepsy \& Behavior 2013 Dec;29(3):527-536. [doi: 10.1016/j.yebeh.2013.09.023]

21. Gu Y, Cleeren E, Dan J, Claes K, Van Paesschen W, Van Huffel S, et al. Comparison between Scalp EEG and Behind-the-Ear EEG for Development of a Wearable Seizure Detection System for Patients with Focal Epilepsy. Sensors 2017 Dec 23;18(1):29 [FREE Full text] [doi: 10.3390/s18010029] [Medline: 29295522]

22. Rich A, Brandes K, Mullan B, Hagger MS. Theory of planned behavior and adherence in chronic illness: a meta-analysis. Journal of behavioral medicine 2015 Aug 21;38(4):673-688. [doi: 10.1007/s10865-015-9644-3] [Medline: 25994095]

23. Bidwell J, Khuwatsamrit T, Askew B, Ehrenberg JA, Helmers S. Seizure reporting technologies for epilepsy treatment: A review of clinical information needs and supporting technologies. Seizure 2015 Nov;32:109-117 [FREE Full text] [doi: 10.1016/j.seizure.2015.09.006] [Medline: 26552573]

24. Lin C, Chen H, Pakpour AH. Correlation between adherence to antiepileptic drugs and quality of life in patients with epilepsy: A longitudinal study. Epilepsy \& Behavior 2016 Oct;63:103-108. [doi: 10.1016/j.yebeh.2016.07.042] [Medline: 27588360]

25. Lua PL, Neni WS. Feasibility and acceptability of mobile epilepsy educational system (MEES) for people with epilepsy in Malaysia. TELEMEDICINE and e-HEALTH 2012 Dec;18(10):777-784 [FREE Full text] [doi: 10.1089/tmj.2012.0047] [Medline: 23078181]

26. Paschal AM, Rush SE, Sadler T. Factors associated with medication adherence in patients with epilepsy and recommendations for improvement. Epilepsy \& Behavior 2014 Feb;31:346-350. [doi: 10.1016/j.yebeh.2013.10.002] [Medline: 24257314]

27. Demonceau J, Ruppar T, Kristanto P, Hughes DA, Fargher E, Kardas P, et al. Identification and assessment of adherence-enhancing interventions in studies assessing medication adherence through electronically compiled drug dosing histories: a systematic literature review and meta-analysis. Drugs 2013 May 16;73(6):545-562 [FREE Full text] [doi: 10.1007/s40265-013-0041-3] [Medline: 23588595]

28. Thakkar J, Kurup R, Laba T, Santo K, Thiagalingam A, Rodgers A, et al. Mobile telephone text messaging for medication adherence in chronic disease: a meta-analysis. JAMA internal medicine 2016 Mar 01;176(3):340-349. [doi:

10.1001/jamainternmed.2015.7667] [Medline: 26831740]

\section{Abbreviations \\ eSM: epilepsy self-management \\ HCP: health care provider \\ PWEs: patients with epilepsy \\ SM: self-management}


Edited by L Buis; submitted 13.07.20; peer-reviewed by K Fitzner, AM Lunde Huseboe; comments to author 11.10.20; revised version received 06.01.21; accepted 24.04.21; published 28.05.21

Please cite as:

Alzamanan MZ, Lim KS, Akmar Ismail M, Abdul Ghani N

Self-Management Apps for People With Epilepsy: Systematic Analysis

JMIR Mhealth Uhealth 2021;9(5):e22489

URL: https://mhealth.jmir.org/2021/5/e22489

doi: $10.2196 / 22489$

PMID:

CMohsen Zaied Alzamanan, Kheng-Seang Lim, Maizatul Akmar Ismail, Norjihan Abdul Ghani. Originally published in JMIR mHealth and uHealth (https://mhealth.jmir.org), 28.05.2021. This is an open-access article distributed under the terms of the Creative Commons Attribution License (https://creativecommons.org/licenses/by/4.0/), which permits unrestricted use, distribution, and reproduction in any medium, provided the original work, first published in JMIR mHealth and uHealth, is properly cited. The complete bibliographic information, a link to the original publication on https://mhealth.jmir.org/, as well as this copyright and license information must be included. 